\title{
A AGENDA FIESP NO GOVERNO DILMA E A DEMANDA POR MAIS ESPAÇOS DE INTERAÇÕES INSTITUCIONALIZADAS
}

\begin{abstract}
Resumo
Na primeira gestão de Dilma Rousseff (2011-2014) ocorreu uma aproximação política do governo junto a Fiesp (Federação das Indústrias do estado de São Paulo). Em maio de 2011, a federação paulista apresentou uma agenda (Brasil do diálogo, da produção e do emprego) com diversas demandas ao governo. Muitas delas, segundo alguns analistas, amplamente postas em prática - como a bilionária política de desonerações fiscais no setor produtivo. Este artigo busca verificar se no conjunto dessas demandas havia propostas para a ampliação ou criação de espaços de interações institucionalizadas e a promoção da inserção dos industriais nos processos de produção de políticas públicas. Para realizar a análise do conteúdo desta agenda, utilizamos a dimensão analítica denominada "capacidade estatal político-relacional", criada por Pires e Gomide (2016). Como resultado dessa análise, verificou-se que a Fiesp, como ator da sociedade civil, demanda propostas que suscita o Estado a mobilizar recursos com vistas a criar capacidades estatais que promovam a interação política entre administração pública e os industriais.
\end{abstract}

Palavras-Chave: Fiesp; Capacidade estatal; Dilma Rousseff; Política pública

\section{INTRODUÇÃO}

Em maio de 2011, início do primeiro mandato de Dilma Rousseff (2011-2014), a Fiesp (Federação das Indústrias do Estado de São Paulo) protagonizou a formalização de uma agenda produtivista, apresentando-a como demanda da entidade ao governo federal. A elaboração desta agenda, denominada "Brasil do Diálogo da Produção e do Emprego" (BDPE), também contou com a participação de centrais sindicais ${ }^{1}$. O documento possui 40 pontos que contemplam variados temas de interesse do empresariado industrial.

O BDPE é organizado em cinco eixos temáticos com destaque para os temas relacionados à macroeconomia (redução dos juros; aumento do crédito; câmbio; indústria e comércio), proteção da indústria nacional, incentivos às compras governamentais, proteção tarifária em relação à indústria chinesa e etc. Diante dessa agenda, pergunta-se: a Fiesp demandou ao governo Dilma a criação ou ampliação de espaços de interação políticas e maior inserção do empresariado na produção de

\footnotetext{
${ }^{1}$ Além da Fiesp, assinam o documento: a Central Única de Trabalhadores (CUT), Força Sindical, Sindicato Metalúrgicos de São Paulo e Sindicato Metalúrgicos de São Paulo, Sindicato dos Metalúrgicos do ABC.
} 
políticas públicas? Fazemos essa pergunta tendo em perspectiva que a demanda por esse tipo de espaço e inserção política indica que o Estado teria condições de mobilizar capacidades estatais e criar mecanismos de coordenação partilhada de políticas públicas com atores sociais.

As dimensões analíticas que tratam de enquadrar as capacidades estatais sob dois aspectos “técnico-administrativo" e "político-relacional” - apresenta por Pires e Gomide (2016) deverão subsidiar o esforço analítico deste artigo. Por que trazer a literatura sobre capacidades estatais para analisar as demandas de uma entidade industrial presentes em um documento? No ciclo de formação de políticas públicas, o Estado mobiliza uma série de capacidades que envolvem tanto aspectos técnicos-administrativos como também aspectos políticos. Essas duas dimensões podem ser mobilizadas pelo Estado na produção de políticas públicas e a esfera "político-relacional" (criação de mecanismos de participação, formulação e coordenação de políticas públicas envolvendo Estado e atores sociais) é uma capacidade estatal sob constante pressão de interesses de diversos segmentos da sociedade civil. Dessa forma, especialmente em regimes democráticos, a dimensão político-relacional ganha um peso importante na formulação de políticas públicas. A inserção de atores sociais no processo de construção dessas políticas é um elemento chave para que o Estado possa legitimar suas ações junto a setores sociais estratégicos. Pelo lado da sociedade civil, a ampliação de capacidades estatais político-relacionais tende a favorecer os interesses de atores da sociedade, já que possibilita maior inserção destes em processos decisórios sobre a alocação de recursos públicos.

O objetivo desse artigo é, utilizando a dimensão analítica "político-relacional" como ponto de partida, aplicar um modelo de análise que nos permita, a partir das demandas presentes no BDPE, mapear se a Fiesp demandou ao governo Dilma (2011-2016) ampliação ou criação de capacidades estatais político-relacional. O artigo é dividido em quatro seções, além desta introdução. Na seção seguinte, o BDPE será apresentado e contextualizado a partir da literatura mais recente que aborda a agenda Fiesp e o governo Dilma. Depois, iremos apresentar o conceito de capacidade "estatal político-relacional" formulado por Pires e Gomide para, posteriormente, apresentar o modelo analítico que propomos para realizar a análise das demandas presentes no BDPE. Na quarta seção, apresentaremos os resultados e as considerações finais. 


\section{A AGENDA FIESP NO PRIMEIRO GOVERNO DILMA ROUSSEFF (2011-2016)}

A iniciativa que resultou no BDPE foi possível a partir da realização de seminários entre a Fiesp e representantes de importantes centrais sindicais no início do primeiro mandato de Dilma Rousseff (2011-2014). Entidades laborais e patronais apresentaram o BDPE ao governo federal como uma iniciativa de união e colaboração frente às vicissitudes da crise econômica mundial iniciada em 2008. A síntese do que norteou a mobilização interclassista era o interesse comum na defesa da "produção e do emprego". Em maio de 2011, em cerimônia solene no Moinho Santo Antônio na capital paulista - local composto por um complexo de indústrias e armazéns que carregam importante simbolismo para o antigo bairro operário da Mooca - a agenda produtivista da Fiesp foi entregue por Paulo Skaf (presidente da federação) ao então vice-presidente da República, Michel Temer. Para além das formalidades que envolvem esse tipo de evento, o BDPE ganha importância por dois motivos: i) pela representatividade que o documento possui, pois demonstra capacidade de atuação coletiva da Fiesp com vistas a ação política direta no Executivo; ii) o documento contém parte substancial da agenda de intervenções na economia promovida no primeiro mandato de Dilma Rousseff, segunda literatura recente que aborda a relação da Fiesp com o governo Dilma - Singer (2014) e Carvalho (2018). O documento sinaliza uma série de questões relacionadas à reivindicações dos industriais: proteção tarifária frente ao produto chinês, regulação para as compras governamentais de conteúdo nacional, ação do governo para reduzir os juros, ação do governo para reduzir as tarifas elétricas, realização de desonerações fiscais, proposta de reformas em conselhos de órgãos da administração pública, por exemplo. Atualmente, a literatura que trata dessa agenda formulada pela Fiesp, a vê como importante elemento para se entender as políticas de intervenção estatal na economia promovidas no primeiro mandato do governo de Dilma Rousseff.

Singer (2014) expõe, em ensaio, que, no primeiro mandato de Dilma (2011-2014), houve uma aliança desenvolvimentista entre o governo e a federação paulista - o autor chama de ensaio desenvolvimentista essa experiência. Singer reúne uma série de políticas públicas e intervenções na economia realizadas por Dilma como evidências de que elas teriam sido utilizadas no sentido dos interesses dos industriais, mais especificamente daquilo que fora formalizado entre a Fiesp e o governo federal no BDPE, em maio de 2011. 
Essa agenda teria sido traduzida em diversas medidas posteriores, como na formulação do Plano Brasil Maior, Singer (2014). Para isso, o autor argumenta que o BDPE teve impacto na condução da nova matriz econômica. Havia, segundo o autor, uma convergência de interesses de uma equipe econômica com ethos desenvolvimentista e de um empresariado interessado em recursos: promover a industrialização e a geração de empregos como forma de enfrentamento à crise econômica iniciada em 2008, estratégia que deveria ser conduzida pelo governo e em linha com os interesses dos industriais. Singer demonstra que essa aliança se rompe no final do primeiro mandato de Dilma quando o governo não consegue mais sustentar o projeto desenvolvimentista perante os humores políticos que se deterioraram com o agravamento da crise econômica. As capacidades estatais exigidas para esse processo, com a presença regulatória do Estado na economia e aumento da participação e influência do empresariado industrial no governo, teriam sinalizado uma rota contrária aos interesses do capital financeiro. Carvalho (2018) trata dos governos petistas, mas foca a análise nos dois mandatos de Dilma Rousseff (2011-2016) e, como Singer, trata também da aliança entre a Fiesp e o governo federal justificada nos ideários da nova matriz econômica. A perspectiva da autora está no campo da economia. Carvalho apresenta a tese de que ao decidir praticar a "Agenda Fiesp" o governo federal acabou aprofundando a crise econômica, principalmente por dois motivos: i) porque, ao seguir as diretrizes da agenda, o governo apostou nas desonerações fiscais no setor produtivo e na expansão do gasto público a patamares excessivamente elevados, em um momento de fragilidade fiscal; ii) porque as desonerações no setor produtivo não produziram os efeitos esperados de aumentar o investimento produtivo privado. Segundo a autora, a intervenção estatal no sentido da promoção da "Agenda Fiesp" teria minado - pelos efeitos negativos que teve nos indicadores econômicos - a confiança dos agentes do mercado financeiro e, em seguida, contaminando as expectativas gerais dos agentes econômicos, o que justificaria o rompimento da Fiesp com o governo, segundo Carvalho (2018). Apesar destes autores partirem de perspectivas teóricas distintas, os dois evidenciam que a Fiesp demandou um conjunto de políticas que invariavelmente colocou o Estado frente a um dilema quanto ao seu papel e capacidade de intervenção na economia. Estes autores constroem suas teses a partir de evidências de políticas públicas criadas e aplicadas pelo governo Dilma que estariam alinhadas a agenda Fiesp apresenta no primeiro trimestre de 2011. Abaixo, segue quadro com o resumo das teses desses autores: 
Quadro 1 - Resumo das teses que envolvem a agenda Fiesp no governo Dilma

Autor

Tese

André $\quad \mathrm{O}$ governo federal teria agido em defesa dos interesses dos industriais, já que possuía um Singer ideário desenvolvimentista, utilizando, para isso, instrumentos estatais de intervenção na economia e ampliado a capacidade do Estado como agente econômico. O documento "Brasil do diálogo da produção e do emprego" apresentado pela Fiesp em 2011 teria composto a base programática que justificou diversas medidas do governo pró indústria durante o primeiro mandato de Dilma. O rompimento da Fiesp com o projeto desenvolvimentista teria ocorrido: a) por conta da ofensiva rentista liderada por agentes do mercado financeiro e; b) por conta do caráter de dupla condição do empresariado - rentista e produtivista - o que torna o empresariado industrial, na conjuntura do neoliberalismo, menos propenso a aceitar às interferências estatais na economia e menos propenso a realizar investimentos produtivos (financeirização).

Laura O governo federal teria agido no sentido de realizar o programa da Agenda Fiesp Carvalho promovendo a intervenção estatal na economia, já que o governo buscava estratégias para manter o vigor do crescimento econômico similar aos mandatos de Lula, mesmo que isso tenha significado a realização de equívocos técnicos na condução da economia. A agenda Fiesp ajudou a aprofundar a crise econômica durante o primeiro mandato de Dilma por ter sido conduzida de forma a privilegiar os interesses da Fiesp, em detrimento da realidade fiscal da economia brasileira. Mesmo assim, a Fiesp teria rompido com Dilma, seguindo a disposição geral dos agentes econômicos que julgavam que o governo cometia uma série de equívocos na economia.

\section{A CAPACIDADE ESTATAL "POLÍTICO-RELACIONAL" A PARTIR DA PERSPECTIVA DO ATOR POLÍTICO}

As dimensões analíticas propostas por Pires e Gomide (2016), com vistas a enquadrar as capacidades estatais - i) dimensão técnico-administrativa; ii) dimensão político-relacional - foram construídas e aplicadas levando-se em consideração a pertinência delas para a análise de políticas públicas. Estas duas dimensões tem como proposta categorizar as capacidades estatais a partir de aspectos técnicos e administrativos, assim como também a partir de aspectos referentes a mecanismos de controle e participação de atores sociais nos processos decisórios. 
O objetivo do Estado, ao mobilizar suas capacidades estatais com vistas à consecução de uma política pública, está embasada no desejo de entregar serviços e produtos públicos, contando, para isso, com alguma legitimidade dos setores sociais que deverão ser afetados pela política pública. Quando trazemos ao foco a capacidade "técnico-administrativa", por exemplo, verifica-se, a partir do conjunto de atributos que compõem essa dimensão, como as variáveis relacionadas estão fundamentadas na burocracia e nos recursos técnicos administrativos estatais. São variáveis ligadas intrinsecamente ao ethos estatal, ao funcionamento da máquina pública. Envolve detalhes que estão ligados ao dia-a-dia do trabalho dos policy makers e da burocracia estatal. Essa esfera é muito mais suscetível ao controle político direto do governo, mesmo quando este esbarra em agências ou estruturas burocráticas com autonomia frente aos interesses governamentais do momento.

Ao trazer a dimensão "político-relacional" ao foco da análise percebemos uma diferença importante em relação a capacidade estatal "técnico-administrativa". Há a inclusão do aspecto relacional envolvendo diretamente a sociedade civil organizada, o que permite extrapolar essa dimensão analítica para além do ethos estatal.

A capacidade do Estado em realizar políticas públicas analisada sob o prisma da dimensão "político-relacional” envolve o enfoque em:

“[...] habilidades e procedimentos de inclusão dos múltiplos atores (sociais, econômicos e políticos) de forma articulada nos processos de políticas públicas, visando à construção de consensos mínimos e coalizões de suporte aos planos, programas e projetos governamentais. Enquanto a primeira dimensão pode ser associada às noções de eficiência e eficácia, a segunda está relacionada com as ideias de legitimidade, aprendizagem e inovação nas ações dos governos.” (Pires e Gomide, 2016, pg. 127)

Diante dessa definição realizada por Pires e Gomide (2016), o Estado, em teoria, teria interesse em mobilizar a sua capacidade político relacional com vistas a buscar, junto a múltiplos agentes da sociedade civil organizada, a elaboração de políticas públicas em conjunto. É uma parceria que, do ponto de vista estatal, torna-se vantajosa, pois: 1) permite legitimar políticas públicas e ajudar a sustentar coalizões, visto que a alocação de recursos para setores específicos da sociedade - via política pública focalizada, por exemplo - pode servir como moeda de troca para apoios políticos e negociações; 2) ao menos em tese, essa aproximação com setores da sociedade 
civil tenderia a trazer novas práticas e expertise na gestão administrativa - mais próxima à realidade do setor privado - pavimentando, assim, o processo de inovação na elaboração de políticas públicas e possibilitando a incorporação de práticas de gestão mais eficientes à burocracia.

Nesse sentido, o Estado busca construir mecanismos de participação e controle de políticas públicas envolvendo o corpo técnico-administrativo estatal à atores da sociedade civil. O Estado, em tese, buscaria também criar espaços de concertação política envolvendo setores sociais específicos. Os espaços de interação institucionalizadas tendem a ser valorizados tanto pelo Estado, como pelos atores da sociedade civil.

A capacidade estatal "político-relacional" é um recurso a ser mobilizado pelo Estado. Mas essa capacidade pode ser também analisada a partir da perspectiva societal, já que, sendo um recurso estatal de interesse dos atores da sociedade civil, a capacidade político-relacional pode ser objeto de demanda (mesmo que de forma não nomeada e difusa) e vista como mecanismo de acesso a recursos públicos. A capacidade "político relacional" não pode ser mobilizada, na prática, pelo ator social. O Estado promove a capacidade "político-relacional” ao perceber as vantagens que ela confere à legitimação da política pública junto a setores sociais estratégicos. Já os atores da sociedade civil, nesse sentido, valorizam a ampliação dessa capacidade estatal ao perceberem as vantagens que ela propicia ao aumentar a inserção deles no processo de formulação de política pública e nas decisões de alocação de recursos.

A promoção de mecanismos compartilhados de controle, participação e monitoramento de políticas públicas resolve, então, dois gargalos. Utilizar a dimensão "político-relacional” para analisar a demanda dos agentes sociais por ampliação desse recurso é diferente da forma originalmente utilizada por Pires e Gomide (2016). Para esses autores, a dimensão "políticorelacional", assim como a dimensão "técnico-administrativa", é um instrumento voltado à análise de políticas públicas concretizadas, não à demandas da sociedade civil em manifestos ou agendas propositivas que, muitas vezes, não são concretizadas.

Dessa forma, cabe, a partir da constatação do aspecto relacional com a sociedade civil presente na dimensão política, construir um modelo analítico que permita utilizar essa dimensão na perspectiva do ator social: a proposta, então, é verificar se a dimensão político relacional utilizada para analisar capacidades estatais pode ser usada também para identificar se a Fiesp demandou a 
ampliação de capacidades políticas do Estado no primeiro mandato de Dilma (2011-2014). Para esse esforço, buscou-se construir um modelo analítico, detalhado na seção seguinte.

\section{UMA ESTRATÉGIA ANALÍTICA PARA A APLICAÇÃO DA DIMENSÃO "POLÍTICO- RELACIONAL" AO CONJUNTO DE DEMANDAS PRESENTES NO BDPE}

É possível identificar demandas no BDPE que acarretariam ampliação da capacidade político-relacional do Estado? Para responder essa pergunta, partimos de que a Fiesp apresentou no BDPE como um conjunto de demandas ao Estado. Se essa agenda subsidiou ou formalizou alguma espécie de pacto político entre a federação paulista e o Estado, conforme sugerem Singer (2014) e Carvalho (2018), reverberando ou não em políticas públicas, não será objeto da presente análise.

Nos interessa verificar se há nessa agenda de demandas da federação paulista - que abarca temas como industrialização, comércio exterior, macroeconômica e a promoção de políticas para a formação de mão-de-obra qualificada - propostas que tenham implicação no aumento da capacidade estatal político-relacional do Estado.

A dimensão política-relacional é fundamentada em variáveis relacionadas à mecanismos de participação e controle de políticas públicas compartilhados, além de interações institucionalizadas com atores da sociedade civil.

Dessa forma, propõe-se verificar neste artigo, partindo da dimensão analítica "político relacional”, se há a presença de demandas no BDPE que envolvem: a) a criação ou ampliação de mecanismos compartilhados de controles de políticas públicas; b) a criação de espaços institucionais de deliberação e concertação política; c) a criação ou ampliação de instrumentos de inserção efetiva do empresariado industrial na formulação e implementação de políticas públicas. Vale notar que a mobilização do Estado com vistas a ampliar as capacidades estatais políticorelacionais pode contar com o apoio de atores da sociedade civil organizada em alguma medida, se estes verificarem que a ampliação dessa capacidade estatal e a inserção deles no aparato estatal tendem a trazer vantagens no acesso a recursos públicos. Abaixo, segue quadro sintetizando o conjunto de variáveis identificadas na dimensão político-relacional e as demandas possíveis a partir delas: 
Quadro 2 - Dimensão Político relacional: síntese das variáveis e “demandas possíveis”.

\begin{tabular}{|l|l|}
\hline Variáveis & Demandas Possíveis \\
\hline Participação formal & Criação ou ampliação de espaços institucionais de \\
& interação entre os industriais e o Estado \\
\hline Participação efetiva & Inserção efetiva dos industriais em processos de \\
\hline Mecanismos de controle & construção de políticas públicas \\
\hline & criação ou ampliação de instrumentos \\
\hline
\end{tabular}

Elaboração: Autor. Variáveis sintetizadas a partir de Pires e Gomide (2016)

Com os três tipos de "demandas possíveis" expostas no quadro anterior, pretendemos utilizá-las como instrumento de análise das demandas do BDPE e verificar se podemos, dentro do conjunto total de demandas, identificar aquelas que, para serem cumpridas, demandaria a mobilização da capacidade estatal político-relacional. O modelo analítico proposto aqui é simples, fundamentado em três etapas: 1) o primeiro passo consiste em, a partir das variáveis que compõe a dimensão político-relacional, organizar eixos "temáticos" de demandas possíveis do ator da sociedade civil sobre a ampliação da capacidade estatal; 2) o segundo passo consiste em mapear as demandas que se encaixam em algum desses três eixos temáticos; 3) o último passo consiste em realizar uma avaliação das demandas mapeadas quanto a implicação delas no incentivo à mobilização da capacidade estatal "político-relacional”. Com esse modelo, pretendemos verificar se a Fiesp incluiu em sua agenda apresentada ao governo Dilma pontos que demandam uma ampliação da capacidade estatal político relacional do Estado. 


\section{RESULTADOS E CONSIDERAÇÕES FINAIS}

Ao enquadrar os 40 pontos do BDPE a partir dos três tipos de "demandas possíveis" que buscam a ampliação ou criação da capacidade político-relacional do Estado, conseguimos identificar quatro demandas da Fiesp nesse sentido. A parte da agenda dedicada ao comércio exterior é a que conta com mais demandas (duas) no sentido de ampliação da capacidade política do Estado. Das duas restantes, uma está presente na parte que cabe às políticas industriais e a outra restante está presente na parte da agenda sobre o incremento de investimentos em desenvolvimento e inovação.

Em um aspecto geral, as quatro demandas estão relacionadas à ampliação ou criação de espaços institucionalizados de coordenação de políticas públicas e a promoção da inserção dos industriais no aparato estatal. As demandas são dirigidas de forma direta ao Estado, solicitando a ampliação de mecanismos estatais de participação. O conjunto de demandas defendidas pela Fiesp, no que se refere a ampliação da capacidade política do Estado, vai no sentido da variável "participação formal".

A demanda por inserção dos industriais no que se refere ao controle de políticas públicas, é bastante claro na parte da agenda que detalha as demandas dos industriais sobre as políticas industriais no âmbito do $\mathrm{PDP}^{2}$. Há, nessa demanda, interesse de inserção dos industriais no aprimoramento dos mecanismos de monitoramento das políticas concernentes ao PDP.

Abaixo segue quadro com o resumo das demandas da Fiesp que implicam na ampliação ou criação de capacidades estatais político-relacionais:

\footnotetext{
${ }^{2}$ Plano de desenvolvimento produtivo: conjunto de políticas industriais elaborada no segundo governo Lula (20072010).
} 
Quadro 3 - Demandas da Fiesp por ampliação da capacidade estatal "político-relacional".

\begin{tabular}{|c|c|c|}
\hline & Demanda & Síntese da demanda \\
\hline 1. & $\begin{array}{l}\text { Aprimoramento institucional } \\
\text { (Política Industrial) }\end{array}$ & $\begin{array}{l}\text { Fortalecimento e inserção dos industriais em conselhos tripartites } \\
\text { do BNDES, FINEP e instituições de coordenação da PDP para } \\
\text { monitoramento, avaliação e acompanhamento de metas - foco nas } \\
\text { metas de conteúdo nacional. }\end{array}$ \\
\hline 2. & $\begin{array}{l}\text { Ambiente de inovação } \\
\text { (Inovação e desenvolvimento) }\end{array}$ & $\begin{array}{l}\text { Criar ambientes estatais de inovação focados nas empresas, } \\
\text { realizando a difusão e extensão tecnológica, aprimorando o } \\
\text { Sistema Brasileiro de Tecnologia SIBRATEC. }\end{array}$ \\
\hline 3. & $\begin{array}{l}\text { Representatividade } \\
\text { institucional e coordenação } \\
\text { (Comércio exterior) }\end{array}$ & $\begin{array}{l}\text { Elevar a representatividade institucional e aprimorar a } \\
\text { coordenação dos órgãos de comércio exterior (MDIC, CAMEX e } \\
\text { COANA/SRF). }\end{array}$ \\
\hline 4. & $\begin{array}{l}\text { Canais de diálogo e } \\
\text { Negociação (Comércio } \\
\text { exterior) }\end{array}$ & $\begin{array}{l}\text { Criar canais formais de diálogo e negociação entre governo e } \\
\text { representações empresariais e de trabalhadores. }\end{array}$ \\
\hline
\end{tabular}

Elaboração: Autor a partir do documento "Brasil do diálogo da produção e do emprego"

O caráter genérico das definições é um traço do documento. O BDPE possui um espírito de pretender estabelecer os marcos gerais dos interesses dos industriais, mesmo partindo da realidade 
específica dos interesses da Fiesp. No conjunto de demandas presentes no documento, sobressai essas descrições genéricas das intenções dos industriais paulistas. Mas há demandas mais específicas, especialmente ligadas a política monetária, proteção alfandegária e desonerações fiscais que, de fato, correm para sanar interesses típicos do empresariado industrial como um todo.

O trabalho original de Pires e Gomide (2016) que aborda a aplicação das dimensões "técnico-administrativa" e "político-relacional" para análise de políticas públicas é feito para o período dos governos petistas recentes. Do conjunto de políticas públicas analisadas por estes autores verifica-se que as capacidades "políticos-relacionais" foram pouco mobilizadas pelo Estado na consecução prática de políticas emblemáticas dos governos Lula e Dilma, como o Minha Casa Minha Vida e o PRONATEC ${ }^{3}$. Das políticas analisadas, há aquelas referentes ao Plano Brasil Maior. Pires e Gomide (2016) indicam que a estratégia industrializante deste plano não contou com a mobilização da capacidade estatal político-relacional.

A apresentação do BDPE ao governo federal ocorreu em maio de 2011. Em agosto de 2011, o governo federal lança o Plano Brasil Maior com o objetivo de reativar a indústria nacional. O resultado proveniente do modelo analítico que aplicamos somados com as observações já feitas por Pires e Gomide sobre o Plano Brasil Maior, nos sugere um descompasso em relação às expectativas de participação compartilhada na elaboração de políticas industriais: a Fiesp, enquanto organização da sociedade civil, demanda maior interação político institucional o que, consequentemente, demanda uma ampliação da capacidade estatal político-relacional, mas a entidade não é atendida pelo Estado.

Este artigo tentou cumprir o objetivo de utilizar a dimensão "político-relacional” como instrumento de análise da agenda proposta pela Fiesp, com vistas a verificar, numa perspectiva do ator social, se a entidade suscitou o Estado no que se refere a ampliar ou criar instrumentos de interação institucionalizada e mecanismos de participação formal dos industriais na elaboração de políticas públicas. Essa natureza de proposta não predomina na agenda, como os próprios resultados demonstram. Mas as que existem sugerem que a federação paulista busca instar o Estado a promover capacidades estatais que aumentem a inserção dos industriais na administração pública, além de demandar maior diálogo político com o setor.

3 PRONATEC: Programa Nacional de Acesso ao Ensino Técnico e Emprego criado no primeiro governo Dilma (2011-2014). Minha Casa Minha Vida:programa de habitação popular criado em 2009 no governo Lula e ampliado nos governos Dilma. 


\section{REFERÊNCIAS}

Carvalho, L.,2018. Valsa brasileira: do boom aos caos econômico. $1^{\circ}$ ed. Todavia. São Paulo.

Nunes, W., 2020. Políticas públicas e construção de capacidades: comparando políticas industriais e sociais no Brasil recente. Revista de Sociologia e Política (no prelo)

Nunes, W., 2018b. Uma estratégia desenvolvimentista sem um "Estado Desenvolvimentista": o caso dos governos Lula. $11^{\circ}$ Encontro Nacional da ABCP. Curitiba

Loureiro, M.R.; Macário, V. \& Guerra, P., 2013. Democracia, arenas decisórias e políticas públicas: o Programa Minha Casa Minha Vida. IPEA. Texto para Discussão, n. 1.886.

Pires, R., \& Gomide, A., 2016. Governança e capacidades estatais: uma análise comparativa de programas. Revista de Sociologia e Política, v. 24, n. 58, p. 121-143.

Pires, R., \& Gomide, A., 2014. Capacidades Estatais e Democracia: arranjos institucionais de políticas públicas. Texto para Discussão, n. 1940, Ipea.

Singer, A., 2014. Cutucando Onças com varas Curtas. Disponível em: https://www.scielo.br/scielo.php?script=sci_abstract\&pid=S0101-33002015000200039\&lng=pt $\underline{\text { \&nrm=iso. }}$. Acesso: $10 / 07 / 2020$. 